\title{
CORRIGENDUM
}

doi:10.1038/nature 16158

\section{Corrigendum: A SUMOylation- defective MITF germline mutation predisposes to melanoma and renal carcinoma}

Corine Bertolotto, Fabienne Lesueur, Sandy Giuliano, Thomas Strub, Mahaut de Lichy, Karine Bille, Philippe Dessen, Benoit d'Hayer, Hamida Mohamdi, Audrey Remenieras, Eve Maubec, Arnaud de la Fouchardière, Vincent Molinié, Pierre Vabres, Stéphane Dalle, Nicolas Poulalhon, Tanguy Martin-Denavit, Luc Thomas, Pascale AndryBenzaquen, Nicolas Dupin, Françoise Boitier, Annick Rossi, Jean-Luc Perrot, Bruno Labeille, Caroline Robert, Bernard Escudier, Olivier Caron, Laurence Brugières, Simon Saule, Betty Gardie, Sophie Gad, Stéphane Richard, Jérôme Couturier, Bin Tean Teh, Paola Ghiorzo, Lorenza Pastorino, Susana Puig, Celia Badenas, Hakan Olsson, Christian Ingvar, Etienne Rouleau, Rosette Lidereau, Philippe Bahadoran, Philippe Vielh, Eve Corda, Hélène Blanché, Diana Zelenika, Pilar Galan, The French Familial Melanoma Study Group, Valérie Chaudru, Gilbert M. Lenoir, Mark Lathrop, Irwin Davidson, Marie-Françoise Avril, Florence Demenais, Robert Ballotti \& Brigitte Bressac-de Paillerets

Nature 480, 94-98 (2011); doi:10.1038/nature10539

In this Letter, one image was mistakenly duplicated during preparation of the artwork. In the original Fig. 3d, the left image illustrating migration of RCC4 cells transduced with empty adenovirus (EV) at $24 \mathrm{~h}$ is a duplicate of the middle image showing migration of RCC4 cells transduced with an adenovirus encoding Mi-WT. The corrected images and migration graph are shown in Fig. 1 of this Corrigendum. This correction does not alter any of the conclusions, and the authors apologize for any confusion this may have caused. Nature has not received a response from the following authors to approve this Corrigendum: V.M., T.M.-D., A.Ro., P.B., E.C. and V.C., and C. Becuwe., J.-L.B., J.C.-B., S.D., C.D., J.L., and K.M. from The French Familial Melanoma Study Group (L.D. is deceased).

d

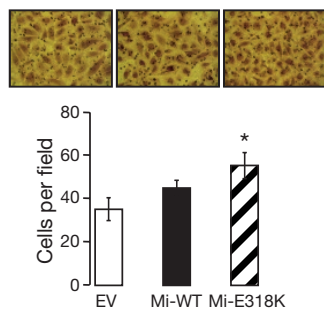

Figure 1 | This is the corrected Fig. 3d of the original Letter. 